\title{
Dry powder inhaled compound delivery for early pre-clinical in vivo efficacy studies
}

\author{
Robert Ives*, Lindsay Butterfield, John Farr, Shaun Bater, Tony Nials, Lewis Entwistle, Doug Ball, Edith Hessel \\ From 2nd Cross Company Respiratory Symposium \\ Horsham, UK. 6-7 September 2012
}

\section{Introduction}

Inhaled dry powders are the preferred route of delivery for many respiratory medicines. Toxicology studies are routinely carried out on inhaled dry powders whereas early pre-clinical in vivo efficacy studies often use aqueous formulations. Ideally evaluation of in- vivo efficacy, duration of action and DMPK of novel compounds, delivered as dry powders, should be carried out at an earlier stage in the drug development process. This would allow direct comparisons to be made with toxicology data to establish a therapeutic index and enable a more relevant prediction of clinical efficacy.

\section{Methods}

We have evaluated the efficacy of Fluticasone Propionate delivered as a dry powder, using an Aerosolised Dust Generation (ADG) tower and a mini-Wrights Dust Feeder II (WDF), in a rat model of LPS induced pulmonary neutrophilia. To more accurately control the doses the animals received we used an Aerosol Particle Sizer (APS) to measure, in real time, the airstream compound concentration. Using this inhaled delivery system allows a more physiologically relevant delivery and distribution to the lungs. The ADG tower and WDF were identical to those used in house for standard safety assessment studies with novel respiratory target molecules.

\section{Results}

We have shown a dose-related inhibition of LPS-induced pulmonary neutrophilia following inhaled delivery of a range of doses of Fluticasone Priopionate. Analysis of lung and plasma concentrations of Fluticasone, plus measurement of airstream compound concentration enabled more accurate dosimetry calculations.

GlaxoSmithKline, Stevenage, UK

\section{Conclusion}

Use of this standard inhaled dry powder delivery technique may more closely link early pre-clinical efficacy and toxicology studies and allow direct comparisons to be made to establish a therapeutic index, and therefore potentially a more relevant prediction of clinical efficacy.

Published: 14 August 2013

doi:10.1186/1476-9255-10-S1-P36

Cite this article as: Ives et al:: Dry powder inhaled compound delivery

for early pre-clinical in vivo efficacy studies. Journal of Inflammation 2013 10(Suppl 1):P36.

Submit your next manuscript to BioMed Central and take full advantage of:

- Convenient online submission

- Thorough peer review

- No space constraints or color figure charges

- Immediate publication on acceptance

- Inclusion in PubMed, CAS, Scopus and Google Scholar

- Research which is freely available for redistribution

\section{()

( 2013 Ives et al; licensee BioMed Central Ltd. This is an Open Access article distributed under the terms of the Creative Commons Attribution License (http://creativecommons.org/licenses/by/2.0), which permits unrestricted use, distribution, and reproduction in any medium, provided the original work is properly cited. 